\title{
EFL Students' Perceptions on stimulated-reflection (VSR) video as a learning strategy to increase speaking performance in Indonesia public university
}

\author{
Nurul Fadhla \\ Universitas Muhammadivah Prof. DR. Hamka, Indonesia \\ *correspondence: nurulfadhla2@gmail.com
}

\begin{abstract}
Video-stimulated reflection has long been used in teaching and learning. One of the uses of videostimulated reflection is in learning the English language. For this reason, this paper discusses students' perceptions in a private university in Jakarta, Indonesia, about applying the method of video stimulated-reflection as a learning strategy to increase speaking performance. There are two objectives in this study. The first objective was to reveal what is the EFL students' perception of video-stimulated reflection. The second objective was to know to what extent the video-stimulated reflection method helps students to enhance students speaking performance. Data were collected via journal reflection and interview. The data were analyzed by content analysis of the qualitative data. Four students of the private university were recruited to participate in this study. They were asked to record their speaking activities and complete journal reflection to capture their voice toward video-stimulated reflection. At the end of this research, an interview was also delivered by these students. The findings show that most students perceived positively toward video stimulated-reflection. Moreover, this study shows the strengths and weaknesses of video reviews; the problem faced when making the video, the aspect that needs to be improved, the efficiency of video stimulated-reflection, and students' focus when viewing the video. The findings are useful for EFL students involved in learning the use of video-stimulated reflection to enhance speaking performance.
\end{abstract}

Keywords: video stimulated-reflection; speaking performance; perception of students EFL

\section{INTRODUCTION}

Reflection is an activity to look back on self, in which individuals engage in-depth thinking to selfevaluate the strength and limitation. Many authors have defined what is called reflection. Reflection is a phase in which individuals participate in careful thought and reflection about their own actions and social circles to improve their behavior (Leinonen et al., 2016). Arp (2016) notes reflection is thus regarded as an activity that, through metacognitive thinking, may enable students to grow their consciousness. Along with this growth, Rosalina et al., (2019) note reflection is an aspect of selfevaluation to observe others' strengths and limitations, which are interrelated in thought and movement.

Video stimulated reflection, also known as video stimulated recall, offers benefit to foreign language students that can improve speaking skills. A study by Chien et al., (2019), In comparison to the non-peer-assessment-based video-stimulated reflection approach, investigate whether learning with the peer assessment approach in video-stimulated reflection will improve students' Englishspeaking performance learning enthusiasm, and critical thinking and decrease their English learning anxiety. The findings show that the peer-assessment-based SVVR approach had more beneficial effects on pupils' Speaking English, learning motivation, and critical thinking, and also decreasing their Learning English anxiety when opposed to the non-peer-assessment-based SVVR method. Another study by López \& Tepetla (2017) examines the influence of video-stimulated reflection of oral taskbased on the growth and development of students' speaking skills. The finding shows that increase vocabulary self-confidence, inspiration, fluency, and improved pronunciation resulted from this 
research intervention. Moreover, Christianson et al., (2009) investigate evaluating the efficacy of videostimulated reflection for academic speaking. The result shows that video-stimulated reflection has been well received by most students and instructors as conducted in the academic speaking course and the large majority recognize that it is an efficient way to develop an understanding of proficiency in spoken English in academic contexts. According to Borg (2006) cited in Schmid (2011) observed that in the 1950s, video-stimulated reflection began to be used in educational research; however, it was not until the 1970s that video-stimulated reflection began to be implemented in the language area cognition research for teachers.

The examination of the previous studies, as discussed earlier, has presented some critical issues concerning the researcher and collecting data. The limitation of the study by $\mathrm{Li}$ (2018) was shown that the researcher was both the control and experimental groups' mentor, which had the potential to induce bias in the results study. Besides, a study by Encalada \& Sarmiento (2019) indicated that the survey was conducted online and that the lack of a qualified interviewer to explain questions could have resulted in less reliable data. The study of applying video simulated reflection as a learning strategy to enhance EFL students' speaking performance in university contexts in Indonesia is understudied. Thus, it is essential to examine the use of video simulated reflection as a learning technique in classrooms speaking EFL students in Indonesia helps increase EFL speaking performance.

This study aimed to investigate students' perceptions of video simulated reflection as a learning strategy to increase EFL students' speaking performance. This research was conducted to determine the efficacy of applying video simulated reflection as a learning technique to improve EFL students' speaking performance. The following research questions will investigate this study:

1. What is the EFL students' perception of video-stimulated reflection?

2. To what extent does the student's video-stimulated reflection strategy help to enhance students speaking performance?

The findings of the current study will significant to the extent they will contribute to the current literature on student's perception of video-stimulated reflection in increase speaking EFL performance. More importantly, recent research may identify the future problem in speaking performance within the Indonesian classroom context and enable the related parties to search for alternative solutions addressing the issues. A video stimulated reflection method was chosen to enable the participants to provide the opportunity to speak in outdoor class and express their perceptions toward method video stimulated reflection.

\section{Video-based Learning}

Currently, video-based learning (VBL) is recognized by the researchers of technology-enhance learning (TEL) as an efficient opportunity for learning in online teaching events Yousef, Chatti, Schroeder (2014). Some of the benefits of video-based learning from several studies (Baloian et al., 2000; Kumar et al., 2001; Piccoli et al., 2001) that summarized in (Zhang et al., 2006), Offers flexibility in time and place; results in budget and time savings for institutions of education; facilitates selfdirected and self-paced learning by enabling practices focused on learners; build a collaborative learning environment by linking each learner with experts and peers who are physically dispersed; enables unrestricted access to electronic education equipment; enables the updating and maintenance of information in more timely and reliable way. Many research studies related to video-based learning.

Shih (2010) carried out a study analysis. This study aimed to develop a hybrid teaching and learning model integrating online and face-to-face instructional blogging for an English course called English public speaking for specific purposes. The research methodology mixed qualitative and quantitative approaches and included input from colleagues and coaches, interviews, self-reflection, and a survey of learning satisfaction. The study involved a total of 44 seniors from college who was majoring in English. Study results showed that if the blended model is implemented with sufficiently supportive equipment and course plans, it could contribute to learning effectiveness and student satisfaction. 
Another study was conducted by Vural (2013). In this study, the focus is primarily on investigated the effect of the interactive online video environment embedded in questions on student achievement. A quasi-experimental design was developed to compare the effectiveness of a questionembedded interactive video environment (QVE) and an interactive video environment without the component in question (IVE). The data were taken from 318 teacher education students enrolled in a computer literacy implementation level course. In order to investigate the impact on student achievement of the question-embedded online video-based environment tool, a quantitative design approach was used. Two quizzes were administered, as were two surveys. The research findings show that the question-embedded video-based environment facilitates learning for students, increasing student engagement and spending time on learning materials.

Moreover, a study by Sun \& Yang (2013) The research was participated by 14 undergraduate students. This current study employs web 2.0 technologies-YouTube and Facebook-as networks to incorporate software. The results suggest that the project strengthened EFL students' public-speaking skills (e.g., growth of ideas and material and pronunciation), actually built their optimism in English speaking, and empowered them to develop their own education process and methods.

\section{Video Stimulated Reflection}

Video stimulated reflection has been researched in the teaching context, but in the speaking, context is underexplored. Gazdag et al. (2019) note that video-stimulated reflection is a helpful methodology for gaining deep insight into the critical thought processes and values of inexperienced teachers, as well as the views that drive their pedagogical work. According to Borg (2006) cite in Schmid (2011), the use of video-stimulated reflection has been proposed as a suitable method of data collection to examine the principles, attitudes, assumptions, hypotheses, and techniques underlying the actions of teachers and their decisions.

Video-stimulated reflection has advantages and limitations. The advantage of video-stimulated reflection is that video-stimulated reflection may evaluate the fundamental thinking behind pedagogical actions and decision-making procedures and patterns. There are limitations of the videostimulated reflection methodology. There are certain constraints: the process is very time-consuming and energy-intensive. Another challenge is that school placements or teaching placements have been carried out in various schools (e.g., the environment, organizational conditions, under the guidance of mentors who perceive different positions, etc.), so they are very difficult to compare (Gazdag et al., 2019).

There is some study that examines the use of video-stimulated reflection in the foreign language teaching context. For example, Gazdag, Nagy, \& Szivák (2019) conducted a study to investigate the benefits of the video-stimulated reflection methodology in teacher education. Interviews were used as a data collection tool in all studies as an attribute of the stimulated reflection technique. The results show that incorporating VSR into teacher education may have several advantages in terms of professional development and dedication to quality improvement. Mulyono (2018) investigate the English foreign language (EFL) teacher talk from teachers' own viewpoints. A video-stimulatedreflection approach was used to collect qualitative data on teachers' impressions of their own teacher speaking. The findings also demonstrate the role of EFL learning beliefs and a good EFL instructor in deciding the amount of instructor speech. Also, Schmid (2011) explores the use of video-stimulated reflection as both a tool of study and as a means of professional development for teachers. Findings based on the study of the abundant amount of data collected suggest that teachers used videostimulated dialogues as effective opportunities for reflection, self-assessment, and pedagogical development.

There have been several studies that conduct a video-stimulated reflection as a learning strategy to enhance speaking performance. A research work conducted by Li (2018) targeted at examining the usefulness of video-assisted stimulated-reflection in teaching EFL students to make oral presentations and the opinions of the students of its pedagogical usage. This research uses a quasi-experimental twogroup pre-test, post-test comparison design that is used to collect data. For 14 weeks, the experimental 
group ( $n=14)$ and the control group $(n=15)$ conducted the same instruction methods, while only the experimental group completed self-reflection that was supported by video. The findings indicated that video-assisted stimulated-reflection successfully improved the use in communication of nonverbal elements by students and that students viewed video-assisted stimulated -reflection as beneficial practices.

Another research was undertaken by Encalada \& Sarmiento (2019). This research sought to classify the impression students had when they self-recorded videos as a way to improve their verbal ability. This research was conducted at two Ecuadorian universities. The researchers used an electronic survey to collect the data to identify the students' perspectives on the use of video-stimulated reflection to develop speech skills. The researchers wanted to examine how participants felt and what suggestions they would provide in future classes to promote the use of this approach or, in the worst case, avoid using this method.

A different study-related video stimulated reflection in a research work conducted by Lefebvre (2015). Examined what categories arise, and then to evaluate what categories and subcategories apply to various estimation styles, review the self-generated feedback of students from their insightful and persuasive speeches. The second purpose of this research is to investigate the similarities and differences between styles of estimation and the ways in which students self-assess their voice. A total of Pupils $(\mathrm{N}=71)$ gave speeches, watched video recordings, and generated self-generated feedback. Findings revealed that when self-evaluating, a greater proportion of students (e.g., under- and overestimators) tended to illustrate feedback norm differences. The lack of perceptual convergence for over-and under-estimators may mean that these students may not understand the fundamental communication skills being taught due to the interrelationship of recognition and implementation skills, especially for public speaking. Perhaps the critical aspect of convergence in interpretation is the precise approach to self-evaluation by estimators.

\section{Mobile Devices}

In recent years, technology-assisted language learning has gained growing attention, and related studies include computer-assisted language learning, mobile-assisted language learning, and language learning that is ubiquitously assisted (Huang et al., 2011). Smartphones, games consoles, digital cameras, video players, netbooks, in-car satellite navigation, and portable computers are all included in mobile devices (Traxler, 2010). Mobile devices provide new opportunities for language education, but their use is still very limited, especially with regard to learning to speak (Youn Ahn \& Lee, 2016). There are many benefits of a mobile device for English foreign language, first, such as simplicity, low cost, the small size of equipment, and user-friendliness (Huang et al., 2011). Second, It helps to address many limitations and barriers faced by the face-to-face classroom of English as a foreign language (EFL), such as a lack of resources for language use, individualized learning, feedback, and interactions (Youn Ahn \& Lee, 2016). Third, self-efficacy, degree of control, and personal significance involved help increase motivation in practice (Oberg \& Daniels, 2013).

There have been several studies that conduct mobile devices as a tool for second language learning. A research work conducted by (Youn Ahn \& Lee, 2016) The goal of that research is to examine user experience of a mobile-based learning program that is improved by speech recognition technology to improve the language skills of the learners of EFL (English as a Foreign Language). Speaking English 60 Junior, which is established in Korea for middle school students, is fitted with automatic speech recognition (ASR) for students' self-regulated speaking practice. It used open-ended survey questions to gain insight into the responses of consumers. The results showed that, generally, the students have positive attitudes towards the program being used to learn how to speak.

Another study related to mobile devices that conducted by Taj, Sulan, Sipra \& Ahmad (2016). This performed meta-analysis of 13 studies published between 2008 and 2015. Four-point standards for choosing analytical research are focused on the year of publication, quasi-experimental design, pretest and post-test technique, and finally, mobile device use for involvement. Analytical findings suggest that mobile-assisted language learning MALL fostered the training on EFL. 


\section{METHODS}

The participants in this study were students from a faculty of teacher training and pedagogy (FTTP) in a private university in Indonesia who take the Department of English education. Participants in this research are non-native speakers. A total of four EFL students was recruited to participate in this research. The fourth names of these participants are disguised.

TABLE 1 Participants

\begin{tabular}{lllll}
\hline Name $^{*}$ & Province & Age & Sex & Education \\
\hline Kinanti & West Jakarta & 22 & F & Bachelor degree \\
\hline Putri & West Jakarta & 22 & F & Bachelor degree \\
\hline Wati & West java & 23 & F & Bachelor degree \\
\hline Wirasti & East Jakarta & 22 & F & Bachelor degree
\end{tabular}

*The participants have been given pseudonyms

The present study uses a qualitative method to identify students' perception in applying video self-reflection to develop speaking skills. A video-stimulated reflection approach was used to collect the data. Orlova's (2009) fourth-phase procedure was adapted, as shown in figure 1 below:

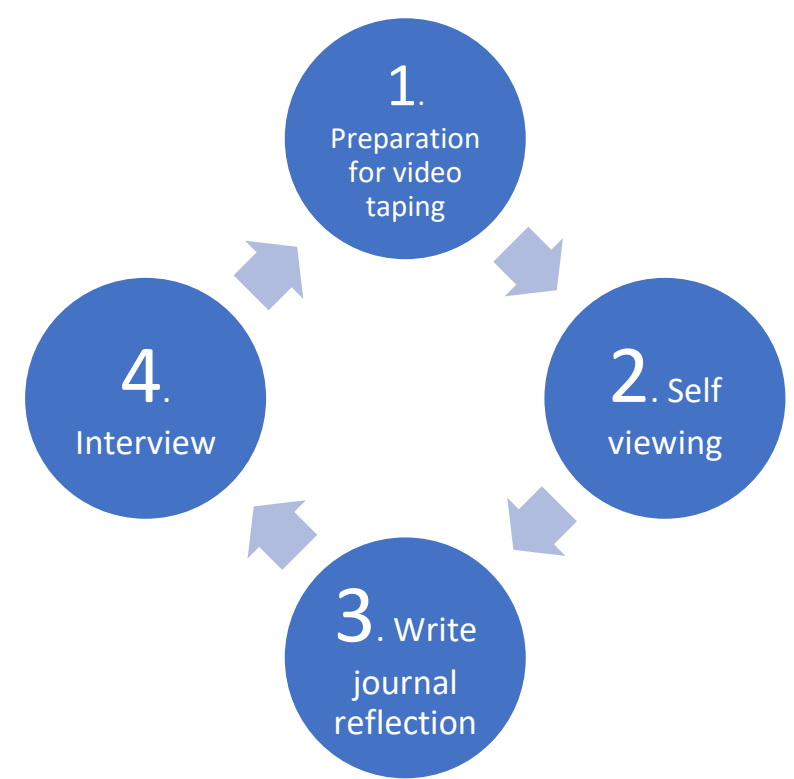

Figure 1. Orlova's (2009) video-elicited reflection procedure

Four-phase procedure:

1) Preparation for videotaping: after determining the schedule and explain activities that will do in this research. Students asked to record their speaking performance. Students are allowed to speak free theme and free time and record themselves from up to bottom.

2) Self-viewing: In this phase, students are asked to view the video which has been made.

3) Write journal reflection: after made a video, students immediately write a journal reflection.

4) Interview: in the fourth phase, the researcher did semi-structured interviews with participants to ask questions about students' perceptions towards method video-stimulated reflection. The interview took approximately 10 minutes. The interview consists of nine questions. A semistructured interview is a verbal exchange where, by asking questions, one person, the interviewer, tries to obtain information from another person (Longhurst, 2003). 
To analyze the result of the study researcher used the qualitative data of the four students' written reflection, and interviews were analyzed using thematic content analysis. There are five steps when analyzing data. In the first step, transcript the reflection journal and semi-structured interview of the four participants, the second step is to read journal reflection and semi-structured interview, the third step is coding journal reflection and semi-structured interview. The coding was based on categories that emerge. The fourth step is combining data according to themes, and the last step is an interview report. The step analysis data are shown in Table Fig 2 below.

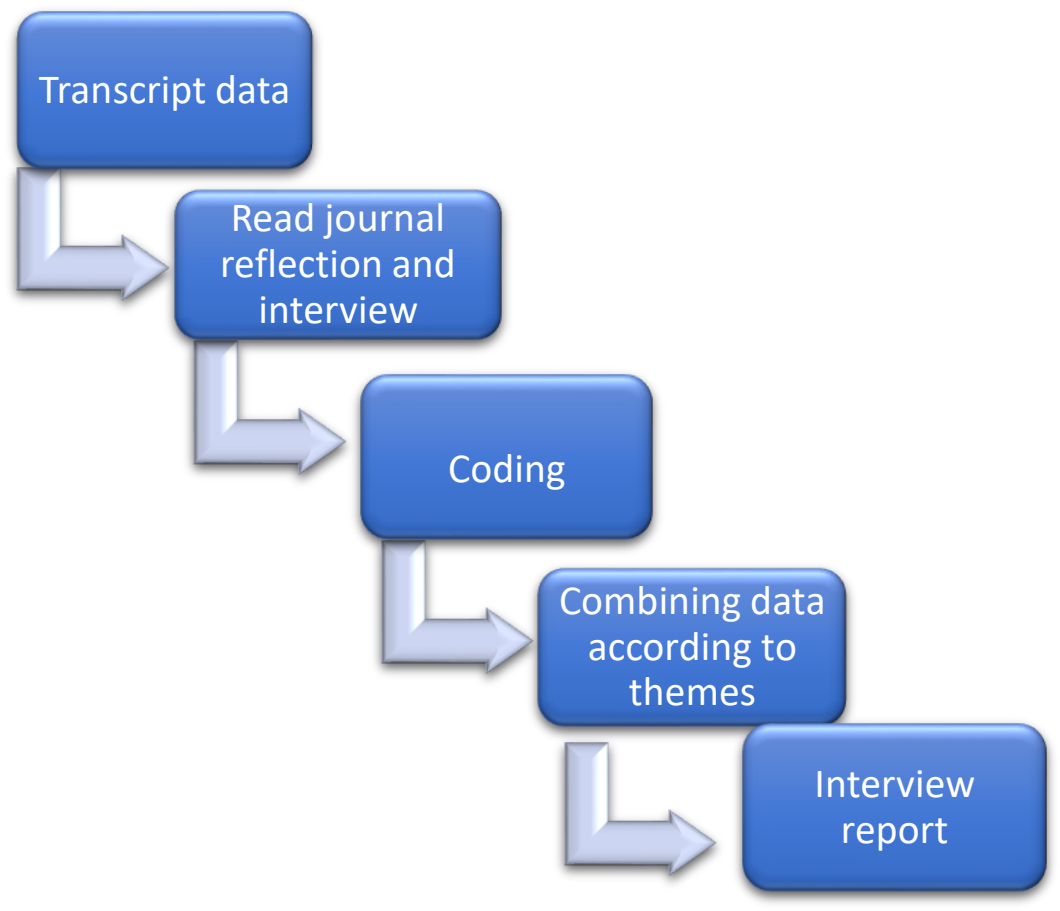

Figure 2. data analysis's process

TABLE 2 Themes and codes.

\begin{tabular}{cl}
\hline Themes & \multicolumn{1}{c}{ Codes } \\
\hline Video review & The strengths \\
& The weakness \\
\hline Problem & Preparing camera \\
& Feelings \\
& Making material \\
\hline Problem & Preparing camera \\
& Feelings \\
& Making material \\
\hline Efficiency & To increase students speaking \\
\hline Students focus & Oral expression \\
& Nonverbal element \\
\hline
\end{tabular}

\section{RESULTS AND DISCUSSION}

In the present study, the structure finding of data using the pattern of (Rosalina et al., 2019). The outcome revealed some students' perception towards the method video stimulated-reflection among others, the strengths and weaknesses of video review, the problem when making the video, the aspect that needs to be improved, the efficiency of video stimulated-reflection, and focus of students when viewing the video.

The strengths and the weakness of video review

\section{Can see the limitations}


The study results demonstrated the strengths of video review. One of the strengths of video review is students can see their limitations when speaking to increase students' future speaking. For example, Wati and Wirasti said in an interview that she be able to see themself when speaking to know the weakness. This was shown in the interview:

"Like in the mirror, so I can see myself. By watching the video, I can improve. for example, the body movements I have to be like this, my pronunciation is like this, it should be better." (Interview Wati).

"The positive thing is I can see myself, oh, I like this. I can see the lack when speaking, how awkward the expression does not exist." (Interview Wirasti)

\section{Feels embarrassing, nervous, and fixated on the lack}

The weakness of video review is that it feels embarrassing, nervous, and fixated on the lack. For example, Putri wrote, she feels embarrassed and nervous when viewing the video. This was shown in: "My feeling when watching my video speaking; I am embarrassed because it turns out I often see the texts. Then I felt nervous because there were pronunciations that I mispronounced." (Journal reflection Putri).

"The negative thing it gets fixated on what I see from the videos I watch. for example when speaking, then watch the video. I think the pronunciation lacks, so I think the pronunciation has to be good in the next video. While it is like body language and vocabulary or grammar out of mind." (Interview Putri)

\section{The problem when making a video Preparing camera}

The present analysis findings have shown that there is some problem when making video among others preparing camera. For example, Kinanti spoke that she got some problems when making the video. Among others preparing the camera and audio. This was shown in an interview:

"The weakness is need effort because I have to prepare the camera, then I also must have a tripod. Noisy is sometimes a problem because many people and my body are too far from the camera; it is also bothersome when making the video. I also have to add sounds all that stuff." (Interview kinanti).

\section{Feels nervous and stammering}

Feelings emerged as a problem when making videos. For example, Wati spoke that she feels nervous and stammering when speaking. This was shown in an interview: "The problem when making the video most basic is still nervous when talking also there is still stammering. Maybe because of the lack of vocab and lack of mastery." (Interview Wati)

\section{Making material}

Another example is based on students Kinanti and Putri. They spoke that material is the problem when making a video. Students felt difficulty when searched material that will deliver to speaking. This was shown in Kinanti and Putri interview:

"Preparing the content is the most important, what kind of content I want to make speaking then how do put the camera, how do I have to stand or sit down, I have to prepare ourselves." (Interview Kinanti).

"The problem maybe because I have to look for material. Sometimes it was not easy, so I had to find the material. Finally, there was not enough time, so it makes me see the text or stuck when speaking, so in my opinion, the time slightly extended." (Interview Putri)

\section{Aspect that needs to be improved Aspect of the target language}

The study results showed that some aspects need to be improved from the aspect of the target language like learn pronunciation, learn vocabulary, fluency. For example, Putri, Kinanti, Wati spoke that aspect that needs to be improved is learned pronunciation and vocabulary. This can be evidence from student answer: 
"In my opinion, the aspect that needs to be improved is pronunciation must often practice, learn vocabulary and more practice at the home." (Interview Putri).

"Fluence and vocabulary because sometimes speak in the camera even though I know the English, because speaking in front of the audience or camera be blank." (Interview Kinanti)

\section{Nonverbal aspect elements}

Nonverbal aspect elements emerged as the aspect that needs to be improved by students when speaking. This was shown in an interview with Wati: "The gesture is still not good and still stiff, the lack of vocabulary, also pronunciation there are still some mistakes." (Interview Wati)

\section{The efficiency of video stimulated -reflection To increase students speaking}

A review of written reflection by students and interviews showed the efficiency of video stimulated reflection. The students expressed that they felt there is enhancement after using video stimulated reflection, the increase in several aspects such as grammar, not read the text, pronunciation, and gesture. For example, Putri spoke that she feels there is an enhancement and change gradually after using the method of video stimulated-reflection, like bringing the full text in the first video, bringing outline in the second video. In the last video, she can speak without bringing text. This was shown in Putri's interview:

"The most stands out when I bring the text because I think the first time, I made a video, I saw myself reading a large text, so I only focused on my text. In the next video, because I had done a reflective, I tried to only make an outline, and it was beneficial when I watch the second video again. Finally, I try not to see the text at all, so the reflective help me." (Interview Putri).

"I think my pronunciation is better than the previous video. For body language, there has been a lot of progress. I have been able to use many gestures. To bring text, this time I didn't bring any text, and for grammar, I have to improve a lot. Because of my videos that I watched, there is still a lot of wrong grammar I pronounced." (Journal reflection Putri)

\section{The focus of students when viewing video Oral expression}

An analysis of the students' written text and interview showed that students focus while viewing the video. There are three categories of student's focus, such as oral expression, nonverbal element, and aspect target language. For example, Kinanti spoke and wrote that hers focus during made videos such as vocabulary, fluency and pronunciation, and speech.

"Vocabulary, fluency, and pronunciation, sometimes I overthink about pronunciation, it was correct yet? It was already fluent or not?" (Interview Kinanti).

"That focused is how I speak, how eye contact dares to look at the camera or not, and our fluency. Because I am not a native speaker, if I speak in English in my brain, I have to switch language from Indonesia to English." (Interview Kinanti)

\section{Nonverbal element}

Another example of students focuses when they view video-based on students Wirasti, Wati and Kinanti they spoke that they focus on nonverbal elements like facial expression, gesture during the speaking and body movements. This was evident in the interview:

"What I focused on is facial expression; it is like I have not expression on the camera and looks stiff. It is also in the second video still looks stiff, but it's now already better than before. it's not like the first video, still confused about what I will say and can't improve." (Interview Wirasti).

"The first definitely that I focused on is the gesture of appearance, from top to bottom, looking at how I am pronunciation and most of the nervousness. There are pauses and filler when nervous." (Interview Wati).

"Keep my attention focused on body movements because my body movements are uncontrollable." (journal reflection Kinanti) 
This research aimed to examine the student's perceptions using tool video stimulated -reflection to increase speaking performance. The central question that was addressed concerned how fourth students perceive the strengths and weaknesses of video review, the problem when making the video, the aspect that needs to be improved, the efficiency of video stimulated -reflection, and the focus of students when seeing the video.

The current study shows the strength of the video review. Through video review, the student can see the lack when speaking to enhancing the upcoming speaking. The positive responses to the activity of the strength video review are in line with previous research (e.g., Christianson, Hoskins, and Watanabe (2009), LeFebvre, LeFebvre, Blackburn \& Boyd (2015). Furthermore, this finding is consistent with Murphy \& Barry (2016), who also shows that the strength of the video review, students gained insights into enhancing future presentations by being able to view their presentations. Also, Wulandari (2019) stated that the Instagram video helped them reflect on their weaknesses in conveying the message.

This current study demonstrated the problem that emerged when making a video. Students mentioned that students feel nervous. In this regard, participants in the research of Christianson (2009) state that among the problem of students when making a video is felt nervous. Additionally, the problem that emerged that face by the student when making the video is sounds. Inline in the results of Putri \& Rahmani (2019) the students mentioned problem that faced during their activities, they faced some of the problems. For example, filming videos: the room's light is too dim to make the video dark, and the surrounding area noisy, to record videos, they used mobile phone cameras, but the video results were not good enough and to get the best results, they have to record videos repeatedly. Also students mention problem that emerged that face by student when making video is needs effort when preparing the cellphone and camera it is in line study by Ting (2013) mention obstacles found while making a video in Window Movie Maker, there were difficulties when working with technology. The equipment and costumes needed to film the video need to be prepared, feel nervous, and have no video shooting experience, a frustrating aspect of video editing. The other problem that arises when making the video feels difficult when search material. Inline, Khojasteh (2013) states there is some problem that faced the student when making a video. These problems ranged from attempting to deal with the assigned topic of students, the lack of English language skills and clothing. Sari (2020) some challenges that faced students when making video projects, such as the weather and other activities with the deadline near.

This current study also demonstrated that aspects that need to be improved from the aspect of the target language like learn pronunciation, learn vocabulary, fluency, and aspect nonverbal element like body movements. The response to the aspect that needs to be improved Encalada \& Sarmiento (2019) state among the aspects that need to be improved, some students experience said that teachers need to teach additional vocabulary so that they can communicate more effectively in the videos.

Furthermore, the efficiency of video stimulated-reflection, among others enhancement after use of video stimulated reflection, increases several aspects such as grammar, not reading the text, pronunciation, and gesture. The responses to the efficiency of video stimulated reflection in context speaking in line research of (Soto et al., 2017) shows that students created a sense of self-awareness of their learning success by engaging in weekly videos as they became aware of the growth in their listening skills, pronunciation, and fluency. Also, Cutrim Schmid (2011) video-stimulated reflection provided participants with effective opportunities to evaluate their reasons for using the technology, assess the influence of IWB on classroom engagement, and monitor their pedagogical progress as IWB users according to the findings of the study. It contrasts with the findings of Sari (2020) revealed that the student's English language skills were not significantly improved compared to the outcome of the self-quality enhancements.

The focus of students while they view the video. There are three categories of students' focus. Such as oral expression, nonverbal elements,_and aspects of the target language. This finding is consistent with preview research by $\mathrm{Li}$ (2018) shows that students concentrated primarily on their use 
of non-verbal elements and oral speech in oral presentations while making video-stimulated reflection, and that video-stimulated reflection was successful in the former area.

\section{CONCLUSION}

The findings revealed that some of the students perceive video-stimulated reflection as one method of teaching the English language that effective in improving EFL speaking performance. Students reported that video-stimulated-reflection could increase their linguistic aspect (vocabulary, pronunciation, grammar), nonverbal elements (gesture, eye contact, body movements). Additional finding revealed there are strengths and weaknesses of video reviews, some problems when making the video. Aspect that needs to be improved, the efficiency of video stimulated-reflection, and focus of students when viewing the video.

Very little research has focused on students' perception of video-stimulated reflection as a method for English foreign language to increase speaking performance. The present study has attempted to enrich the literature on students' perception toward using video-stimulated reflection in speaking context for EFL. There is some limitation in this study, among others. Firstly, there is no male in this study to produce more generalizable outcomes and need male participants. Secondly, this research only knows the perception of students EFL toward the use of video-stimulated reflection for increased speaking performance. There is a need for quantitative data collection to know precisely the effectiveness of method video-stimulated reflection for increase speaking performance.

\section{REFERENCES}

Arp, A. (2016). Examining Student Metacognition when Self-Evaluating Public Speaking.

Baloian, N. A., Pino, J. A., \& Ulrich Hoppe, H. (2000). A teaching/learning approach to CSCL. Proceedings of the 33rd Hawaii International Conference on System Sciences - 2000, 447-456. https://doi.org/10.1109/hicss.2000.926641

Chien, S.-Y., Hwang, H., \& Siu-Yung Jong, M. (2019). Effects of Peer Assessment within the Context of Spherical Video-based Virtual Reality on EFL students' English-Speaking Performance and Learning Perceptionse. Computers \& Education.

Christianson, M., Hoskins, C., \& Watanabe, A. (2009). Evaluating the effectiveness of a videorecording based self-assessment system for academic speaking. Language Research Bulletin, 24, 115.

Cutrim Schmid, E. (2011). Video-stimulated reflection as a professional development tool in interactive whiteboard research. ReCALL, 23(3), 252-270. https://doi.org/10.1017/S0958344011000176

Encalada, M. A. R., \& Sonia Magali Arteaga Sarmiento. (2019). Perceptions about Self-recording Videos to Develop EFL Speaking Skills in Two Ecuadorian Universities. Language Teaching and Research, 10(1), 60-67. https://doi.org/http://dx.doi.org/10.17507/jltr.1001.07

Gazdag, E., Nagy, K., \& Szivák, J. (2019). "I Spy with My Little Eyes..." The use of video stimulated recall methodology in teacher training - The exploration of aims, goals and methodological characteristics of VSR methodology through systematic literature review. International Journal of Educational Research, 60-75. https://doi.org/10.1016/j.ijer.2019.02.015

Huang, Y. M., Huang, Y. M., Huang, S. H., \& Lin, Y. T. (2011). A ubiquitous English vocabulary learning system: Evidence of active/passive attitudes vs. usefulness/ease-of-use. Computers and Education. https://doi.org/10.1016/j.compedu.2011.08.008

Kumar, A., Kumar, P., \& Choton Basu, S. (2001). Student Perceptions of Virtual Education: An Exploratory study. Managing Information Technology in a Global Economy, the Proceedings of the Information Resources Manage- Ment Association International Conference, 400-404. http://www.ideagroup.com

Lefebvre, L., Lefebvre, L., Blackburn, K., \& Boyd, R. (2015). Student Estimates of Public Speaking Competency: The Meaning Extraction Helper and Video Self- evaluation. Communication Education, 64(3), 261-279. https://doi.org/10.1080/03634523.2015.1014384 
Leinonen, T., Keune, A., Veermans, M., \& Toikkanen, T. (2016). K-12 education. 47(1), 184-202. https://doi.org/10.1111/bjet.12224

Li, X. (2018). Teaching English oral presentations as a situated task in an EFL classroom : A quasiexperimental study of the effect of video- assisted self-reflection Enseñanza de presentaciones en inglés como tarea situada en el. REVISTA SIGNOS. ESTUDIOS DE LINGÜÍSTICA, 51(98), 359-381. https://doi.org/10.4067/S0718-09342018000300359

Longhurst, R. (2003). Semi Structured Interview and Focus Group. Key Methods in Geography, 103-115.

Mohamed, A., Yousef, F., Chatti, M. A., \& Schroeder, U. (2014). Video-Based Learning: A Critical Analysis of The Research Published in 2003-2013 and Future Visions. 112-119.

Murphy, K., \& Barry, S. (2016). Feed-forward: students gaining more from assessment via deeper engagement in videorecorded presentations. Assessment \& Evaluation in Higher Education, 41(2), 213-227. https://doi.org/10.1080/02602938.2014.996206

Oberg, A., \& Daniels, P. (2013). Analysis of the effect a student-centred mobile learning instructional method has on language acquisition. Computer Assisted Language Learning, 26(2), 177-196. https://doi.org/10.1080/09588221.2011.649484

Orlova, N. (2009). Video Recording as a Stimulus for Reflection in Pre-Service EFL Teacher Training. English Teaching Forum, 47, p30-35. http:/ / eric.ed.gov/?id=EJ923452

Piccoli, G., Ahmad, R., \& Ives, B. (2001). Web-based virtual learning environments: A research framework and a preliminary assessment of effectiveness in basic it skills training. MIS Quarterly, 25(4), 401-426. https://doi.org/10.2307/3250989

Putri, R. N., \& Rahmani, B. D. (2019). Students Perception on Using Video Recording to Improve Their Speaking Accuracy and Fluency. UHAMKA International Conference on ELT and CALL (UICELL), November, 21-22.

Rosalina, R., Mulyono, H., \& Dewi, N. K. (2019). Reflective teaching of an in-service EFL teacher to improve a professional skill. ICASI. https://doi.org/10.4108/eai.18-7-2019.2288651

Sari, A. B. P., Dardjito, H., \& Dinar, M. A. (2020). EFL students' improvement through the reflective youtube video project. International Journal of Instruction, 13(4), 393-408. https://doi.org/10.29333/iji.2020.13425a

Shih, R. (2010). Blended learning using video-based blogs : Public speaking for English as a second language students. Australasian Journal of Educational Technology, 26(6), 883-897.

Soto, S. T., Cevallos, L. F. E., \& Fontaines-Ruiz, T. (2017). How does explaining content through videos benefit language learners? ESP students tell us about it. Turkish Online Journal of Educational Technology, 385-391.

Sun, Y., \& Yang, F. (2013). I help, therefore, I learn: service learning on Web 2 . 0 in an EFL speaking class. December 2014. https://doi.org/10.1080/09588221.2013.818555

Taj, I. H., Sulan, N. B., Sipra, M. A., \& Ahmad, W. (2016). Impact of mobile assisted language learning (MALL) on EFL: A meta-analysis. 7(2). https://doi.org/10.7575/aiac.alls.v.7n.2p.76

Ting, N. C. (2013). Classroom Video Project: An Investigation on Students Perception. Procedia - Social and Behavioral Sciences, 90, 441-448. https://doi.org/10.1016/j.sbspro.2013.07.113

Traxler, J. (2010). Students and mobile devices. ALT-J: Research in Learning Technology, 18(2), 149-160. https://doi.org/10.1080/09687769.2010.492847

Vez López, E., \& Bertani Tepetla, V. (2017). The impact of self-video recordings in raising oral production. $76-$ 101. https://doi.org/10.15446/male.n11.71855

Vural, Ö. F. (2013). The impact of a question-embedded video-based learning tool on E-learning. 13(2), 13151323.

Wulandari, M. (2019). Improving EFL learners' speaking proficiency through instagram vlog. LLT Journal: A Journal on Language and Language Teaching, 22(1), 111-125.

Youn Ahn, T., \& Lee, S. (2016). User experience of a mobile speaking application with automatic speech recognition for EFL learning. 47(4), 778-786. https://doi.org/10.1111/bjet.12354

Zhang, D., Zhou, L., Briggs, R. O., \& Nunamaker, J. F. (2006). Instructional video in e-learning: Assessing the impact of interactive video on learning effectiveness. Information and Management, 
Nurul Fadhla

43(1), 15-27. https://doi.org/10.1016/j.im.2005.01.004

Zulaiha, S., \& Mulyono, H. (2018). Preservice EFL teachers' talk during a teaching practicum at a lower secondary school: A report on video-stimulated reflection (VSR ). Argentinian Journal of Applied Linguistics, 6(1), 44-60. 